\title{
Selected topics from the 27th International Colloquium on the Dynamics of Explosions and Reactive Systems, Beijing, China, July 28-August 2, 2019
}

\author{
G. Ciccarelli ${ }^{1}$
}

Published online: 2 December 2020

○) Springer-Verlag GmbH Germany, part of Springer Nature 2020

This issue contains selected papers that were presented at the 27th International Colloquium on the Dynamics of Explosions and Reactive Systems (ICDERS) held in Beijing, China, on July 28-August 2, 2019. The biennial ICDERS is the reference meeting focusing specifically on dynamic aspects of reactive systems. The local organization was headed by Peking University with J.P. Wang as the chair of the committee. The program committee was chaired by G. Ciccarelli and co-chaired by J. Kasahara and E. Petersen, with the assistance of B. Akih, R. Bauwens, J. Bergthorson, Y.-C. Chao, N. Chaumeix, A. Chinnayya, J.-Y. Choi, A. Comandini, S. Dorofeev, T. Endo, M. Fotia, V. Gamezo, A. Higgins, K. Ishii, S. Jackson, I.-S. Jeung, F. Marra, A. Matsuo, R. Mevel, S. Navarro-Martinez, H.-D. Ng, M. Radulescu, S. Shy, P. Vidal, B. Wang, and J. Wen.

A total of close to 400 participants attended the conference, of which 295 delivered oral presentations and 71 presented posters on explosions, detonations, ignition, turbulent combustion, and other topics in combustion. With more than 20 countries represented, the conference is truly international. As in previous years, presenters at the conference were encouraged to submit their work to a selection of three journals depending on the research topic. The current issue includes papers dealing with combustion in high-speed flow and shock waves, detonation, and deflagration-to-detonation transition, whose authors elected to submit to Shock Waves. A second ICDERS issue dealing with pressure gain combustion is being compiled by E. Gutmark. Submissions were subjected to the same rigorous peer review process as a regular submission to Shock Waves. Each paper was reviewed by at least two independent referees, each of whom is an internationally recognized expert in the field.

Twenty-one papers from the conference were submitted to the current special issue, of which thirteen were eventually accepted, upon two or more revisions, after the referees and the editor reached a consensus. Six papers were rejected, one paper was withdrawn, and one was transferred to the Pressure Gain Combustion thematic issue for evaluation.

The current issue includes papers that fall into the following broad topic areas mainly dealing with detonation wave dynamics. The papers appear in the issue in this order. There are two papers on detonation structure, two papers on near limit detonation propagation in smooth channels, three papers on detonation initiation and propagation in obstacleladen channels, three papers looking at detonation wave chemistry-effects, two papers on numerical simulation of detonation waves, and one paper on blast loading in enclosures. Geographically, the papers originated from Canada, China, Japan, Russia, South Korea, and the USA.

I wish to thank the authors who submitted their papers to this issue and then revised their papers numerous times in order to produce the best quality possible. I would also like to thank the many reviewers whose help was crucial in ensuring the high quality of the papers that appear in this issue. I would like to thank both the authors and reviewers for their quick responses despite the very trying times we find ourselves in this past year.

Publisher's Note Springer Nature remains neutral with regard to jurisdictional claims in published maps and institutional affiliations.
G. Ciccarelli

gaby.ciccarelli@queensu.ca

1 Department of Mechanical and Materials Engineering, Queen's University, 130 Stuart Street, McLaughlin Hall, Kingston, ON K7L 3N6, Canada 